\title{
MySOMOI: An interdisciplinary platform that promotes wholesome oral health
}

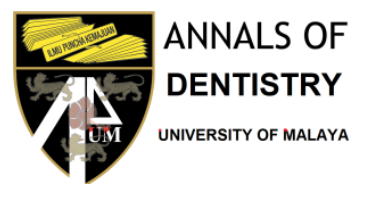

www.adum.edu.my

Ann Dent UM 2018, 25(2): 32-33 Dol: 10.22452/adum.vol25no2.2

\author{
Mohd Hafiz Arzmi ${ }^{1 *}$, Intan Azura Shahdan ${ }^{2}$
}

The Editor

Annals of Dentistry

Dear Professor,

Like many other developing countries, dental caries posed important health problems among children and adults in Malaysia. Lack of awareness on oral health has been suggested as the predisposing factor that might have contributed to dental caries. As a customary practice, oral health promotion is often carried out by dentists themselves, whose practice are regulated by Act 51, Dental Act 1971 an act that ensures the safety of the patients in the country. However, non-dentists who are working towards promoting good oral health practice are almost scarce or even non-existed at the national level. Moreover, the incidence of a fraud dentist who was caught in 2017 has sent several messages with regards to the level of public awareness on the implications of unqualified dental treatments. The act has since been revised and is now named Act 804, Dental Act 2018.

It is only timely that an organization is formed to complement the efforts made by the government and dental professionals in combating caries. It is for this reason, that we are introducing the Malaysian Society of Oral Microbiologists and Oral Immunologists (MySOMOI), a national and nonprofit organization that was established on $17^{\text {th }}$ of July, 2018 (https://mysomoi.org). The mission of the society is to unite academician, researchers, practitioners, industrialists and policymakers in promoting awareness and best practices in oral health with a vision of achieving oral health for a healthy life. MySOMOI upholds the spirit, morals, and motivation to ensure holistic healthy living for

${ }^{1}$ Kulliyyah of Dentistry, International Islamic University Malaysia, Kuantan Campus

${ }^{2}$ Kulliyyah of Allied Health Sciences, International Islamic University Malaysia, Kuantan Campus

*Correspondence: hafizarzmi@iium.edu.my today and tomorrow. Hence the core values of the society are comprised of: Sincerity, Commitment, Innovation, Empathy, Networking, Trust, Integrity, Fairness, Intellectuality and Creativity, representing the acronym "SCIENTIFIC". The specific objectives of MySOMOI are to:

- promote and facilitate the advancement of the Immunological and Microbiological aspects of oral health.

- share, disseminate, and exchange of information relating to Oral Microbiology and Oral Immunology (OMOI) at both national and international levels.

- facilitate ethical standards in fundamental and applied research as well as product development and commercialization in the field of $\mathrm{OMOI}$ in Malaysia.

The history of MySOMOI begins from the idea of having an interdisciplinary platform for Oral Microbiologists and Oral Immunologists. On $13^{\text {th }}$ of April, 2018, the constitution of MySOMOI was finally endorsed during the formation meeting held at the Faculty of Dentistry, University of Malaya which was attended by 29 members of the Advisory Board from different disciplines namely Dentistry, Medicine, Immunology and Microbiology from various universities from Malaysia and abroad. During the formation meeting, 11 members were elected to form the Protem Committee, and on $17^{\text {th }}$ of July, 2018, MySOMOI was successfully endorsed by the Malaysian Registrar of Societies Department as a registered professional body in Malaysia.

Given the need for a more effective integration in the field of Oral Immunology and Oral Microbiology, MySOMOI has agreed to become the co-organizer for the International Conference on Oral Microbiology and Oral Immunology (ICOIOM), held on $14-15^{\text {th }}$ of August, 2018. ICOIOM 2018 was participated by about 80 registered participants from Australia, Bangladesh, Belgium, India, Indonesia, Japan, New Zealand, UAE, USA and 
Malaysia and has fruitfully formed a bridge between clinicians, dentists and scientists alike. Not only that, participants of ICOIOM had demonstrated the evidence of remarkable supports and interests to have a strong connection of leaders in both oral microbiology and immunology fields at the regional level. In addition to oral and poster presentations, ICOIOM was also unique as it provided a platform for participants that were not able to attend the conference to present virtually, via e-Poster and Google hangouts. Notably, members of MySOMOI seized the opportunity during ICOIOM to conduct our first Biennial General Meeting and the historical meeting was launched by the Honorable Vice Chancellor of University of Malaya, Datuk Ir. Dr Abdul Rahim Hashim.

It is with our greatest pleasure to invite all readers to becoming members and supporters for MySOMOI. In the coming months, we are installing many community engagements and would look forward to collaborate with all parties that are interested in encouraging good oral hygiene

Thank you.

License Information: This work is licensed under a Creative Commons Attribution 